\title{
O ENSINO DE FRANCÊS NO NÚCLEO DE LÍNGUAS DA UNIVERSIDADE FEDERAL DO ESPÍRITO SANTO DURANTE PANDEMIA DE COVID-19
}

\author{
LA ENSEÑANZA DEL FRANCÉS EN EL NÚCLEO DE LÍNGUAS DE LA \\ UNIVERSIDADE FEDERAL DO ESPÍRITO SANTO DURANTE LA PANDEMÍA POR \\ COVID-19
}

\begin{abstract}
TEACHING FRENCH AT LANGUAGE CENTER OF FEDERAL UNIVERSITY OF ESPÍRITO SANTO DURING THE COVID-19 PANDEMIC
\end{abstract}

Grace Alves da PAIXÃO ${ }^{1}$ Igor Castilho PORSETTE2

RESUMO: Relata-se a experiência de ensino de Francês Língua Estrangeira (FLE) no Núcleo de Línguas da Universidade Federal do Espírito Santo (NL-UFES) no primeiro semestre letivo de 2020, no contexto da pandemia da Covid-19. O objetivo é registrar uma realidade determinada e, a partir desse contexto, discutir questões atinentes ao ensino-aprendizagem de francês. O estudo baseou-se em documentos como atas de reuniões, portarias institucionais, pesquisas realizadas pelo NL-UFES junto ao alunado e em levantamentos de dados sobre matrículas efetuadas e evasão. As reflexões têm aportes teóricos de Magnoni e Silva (2014), Galli (2012), Kaspary (2012), Bianchini (2003) e Nitzke (1999). As conclusões apontam para as dificuldades de permanência dos alunos nos cursos face ao novo contexto, para as adaptações metodológicas necessárias na passagem do presencial ao virtual e para as formas de avaliação não tradicionais que a nova realidade faz emergir.

PALAVRAS-CHAVE: Educação. Ensino de FLE. Ensino remoto. Covid-19

RESUMEN: Reportamos la experiencia de enseñar Francés Lengua Extranjera (FLE) en el Núcleo de Línguas de la Universidade Federal do Espírito Santo (NL-UFES) en el primer semestre académico de 2020, en el contexto de la pandemia por Covid-19. El objetivo es registrar una realidad especifica y, desde este contexto, discutir temas relacionados con la enseñanza y el aprendizaje del francés. El estudio se basó en documentos como minutas de reuniones, ordenanzas institucionales, investigaciones realizadas por el NL-UFES con los estudiantes y datos sobre matrículas y evasión. Las reflexiones cuentan con aportes teóricos de Magnoni y Silva (2014), Galli (2012), Kaspary (2012), Bianchini (2003) y Nitzke (1999). La conclusión general es a las dificultades de permanencia de los estudiantes en los cursos ante el nuevo contexto, las adaptaciones metodológicas necesarias en la transición de la clase a lo virtual y las formas de evaluación no tradicionales que trae la nueva realidad.

PALABRAS CLAVE: Educación. Enseñanza de FLE. Enseñanza virtual. Covid-19.

\footnotetext{
${ }^{1}$ Universidade Federal do Espírito Santo (UFES), Vitória - ES - Brasil. Professora Adjunta de Língua e Literatura Francesa no Departamento de Línguas e Letras. Doutorado em Letras (USP). ORCID: https://orcid.org/0000-00022605-2840. E-mail: grace.paixao@ufes.br

${ }^{2}$ Universidade Federal do Espírito Santo (UFES), Vitória - ES - Brasil. Professor Adjunto de Língua e Literatura Italiana no Departamento de Línguas e Letras. Doutorado em Letras Neolatinas (UFRJ). ORCID: https://orcid.org/0000-0003-4846-5723. E-mail: igor.porsette@ufes.br
} 
ABSTRACT: We report the experience of teaching French as a Foreign Language in the Language Center of the Federal University of Espirito Santo (NL-UFES) in the first academic semester of 2020, in the context of the pandemic by Covid-19. The focus of this study is to register a specific reality and, from this context, discuss topics related to learning French. The research was based on documents such as minutes of meetings, institutional ordinances, investigations carried out by the NL-UFES with students and data on enrollments and evasion. For our reflection about this subject, in this paper, we used theoretical contributions from de Magnoni and Silva (2014), Galli (2012), Kaspary (2012), Bianchini (2003) and Nitzke (1999). The conclusions point to the difficulties of the students remaining in the courses in the face of the new context, to the methodological adaptations necessary in the transition from classroom to virtual and to the non-traditional forms of assessment that the new reality makes emerge.

KEYWORDS: Education. FFL teaching. Remote teaching. Covid-19.

\section{Introdução}

Embora o ensino remoto de línguas estrangeiras (LEs) esteja longe de ser uma novidade (MAGNONI; SILVA, 2014), o ano de 2020 foi significativo para este campo do saber, em virtude da pandemia de Covid-19, porque, diante do cenário de isolamento social, houve necessidade de se reinventarem práticas pedagógicas em espaços tradicionalmente presenciais. Nesse sentido, impôs-se ao Núcleo de Línguas da Universidade Federal do Espírito Santo (NLUFES) o desafio de repensar o ensino de idiomas em um contexto novo.

O objetivo deste artigo é relatar a experiência de ensino de francês no NL-UFES, apontando as dificuldades encontradas e as soluções propostas na tentativa de transposição do ensino presencial para o ensino remoto em caráter emergencial, levando em consideração: aspectos do contexto da pandemia no Brasil e no Espírito Santo; seus impactos para cotidiano da UFES; fatores psicoafetivos e estruturais e as adaptações às ferramentas do ensino remoto.

O presente relato compartilha experiências que, tendo sido vivenciadas no âmbito do NL-UFES, podem ilustrar perspectivas e concepções de realidades diversas. Tal registro do ensino de francês língua estrangeira (FLE) em uma localidade determinada e em um momento preciso pode dar a ver aspectos de práticas metodológicas e avaliativas, formação continuada e uso de Tecnologias Digitais da Informação e Comunicação (TDICs) no ensino de LE.

Para subsidiar nossas reflexões, contamos com dados cedidos pelo NL-UFES, tais como: quantitativo de estudantes ativos no sistema e efetivamente frequentes às aulas; atas de reuniões; questionários prospectivos e avaliativos realizados antes e depois do ensino remoto.

Configura-se, desta forma, uma pesquisa de abordagem qualitativa, de natureza básica e objetivos exploratórios e descritivos, porque se trata de um aspecto ainda pouco pesquisado 
no Espírito Santo, isto é, os novos cenários do ensino de FLE no contexto da pandemia e a adaptação do ensino presencial ao remoto emergencial.

Para tanto, a discussão estará organizada da seguinte maneira: explanaremos brevemente aspectos do avanço da pandemia no Espírito Santo e seus impactos no cotidiano da UFES; em seguida traremos as ações tomadas no âmbito do NL-UFES diante do novo cenário; descreveremos a realidade do curso de francês ofertado pela instituição e traçaremos um perfil do alunado frente ao acesso às TDICs. A partir desse contexto, relataremos as primeiras interações virtuais, a implementação do ensino remoto, as adaptações metodológicas e as formas de avaliação adotadas. Além disso, propomos uma discussão sobre a evasão nos cursos, em decorrência da nova realidade.

\section{O avanço da pandemia no Espírito Santo e os impactos no cotidiano da UFES}

Não se pretende aqui traçar pormenores do avanço da pandemia em território espíritosantense, mas apontar em linhas gerais os impactos da chegada do vírus para o cotidiano da Universidade - no intuito de evidenciar os desafios que seriam enfrentados pela gestão da instituição e, consequentemente, pela comunidade acadêmica como um todo - e ilustrar assim o contexto do NL-UFES.

Nos cursos de idiomas do NL-UFES, o primeiro semestre letivo de 2020 iniciou-se em fevereiro, quando a pandemia da Covid-19 já atingia fortemente a Ásia e a Europa. Em solo brasileiro, não havia casos oficialmente confirmados e, por isso, não havia nenhuma medida de restrição ao convívio social, ou seja, a rotina dos brasileiros ainda não tinha sido alterada.

No início de março, a doença chegou no Espírito Santo (GOVERNO DO ESPÍRITO SANTO, 2020a), o que levou as autoridades locais a tomarem medidas mais efetivas para tentar conter o seu avanço. Nesse sentido, em meados daquele mês, o governo do Estado e as prefeituras determinaram a paralisação das atividades consideradas não essenciais, como as aulas em escolas, cursos e faculdades (GOVERNO DO ESPÍRITO SANTO, 2020b; PREFEITURA DE VITÓRIA, 2020).

Seguindo as diretrizes estaduais, no dia 16 de março, a UFES suspendeu as atividades do restaurante universitário, as autorizações para viagens domésticas e internacionais, as aulas presenciais dos cursos de graduação e de pós-graduação e os eventos coletivos, no período de 17 a 29 de março e manteve as atividades de pesquisa, de extensão e administração a serem realizadas unicamente em caráter remoto. Posteriormente, mantendo o calendário acadêmico, a 
suspensão das atividades presenciais foi prorrogada por períodos que variavam de quinze dias a um mês (UFES, 2020b; 2020c; 2020d; 2020e).

Entre abril e agosto de 2020, as aulas de graduação e de pós-graduação permaneceram suspensas em qualquer modalidade, enquanto a Reitoria promovia ações como: criação de um grupo para pensar o retorno das aulas (UFES, 2020f); envio de pesquisa on-line aos(as) estudantes, a fim de identificar as condições de acesso às TDICs (UFES, 2020g); discussões acerca de um Plano de Biossegurança e de um Plano de Contingência, (UFES, 2020h; 2020i); e preparação da comunidade para o trabalho remoto (UFES, 2020j; UFES, 2020k).

Entretanto, uma volta efetiva às aulas, na modalidade remota, veio a ser implementada somente a partir do mês de setembro no âmbito da graduação e pós-graduação da UFES. Para o NL-UFES, de acordo com seus gestores, a espera pelo retorno na graduação implicaria em um impacto financeiro significativo, podendo comprometer até mesmo a continuidade do projeto, como esperamos deixar claro mais adiante.

Para tanto, na próxima seção, trataremos das primeiras ações tomadas no âmbito no Núcleo de línguas da UFES, que tiveram o objetivo de dar continuidade ao trabalho, visando à continuidade do projeto extensionista de cursos de línguas para a comunidade.

\section{As ações no âmbito do núcleo de línguas da UFES}

O NL-UFES ocupa uma posição bastante peculiar entre as instâncias da Universidade: por um lado, é ligado administrativamente ao Centro de Ciências Humanas e Naturais (CCHNUFES), funcionando como um centro agregador de diversos projetos extensionistas, dentre eles os cursos de idiomas; por outro lado, é gerido pela Fundação para o Desenvolvimento do Espírito Santo (FEST), o que lhe confere relativa autonomia.

A autonomia do Núcleo de Línguas se dá, por exemplo, na definição de um calendário próprio de atividades, não seguindo o calendário acadêmico, na possibilidade de contratar funcionários em regime de CLT ligados à fundação de apoio e não à Universidade e na cobrança de taxas pelos serviços prestados, uma vez que os projetos não têm apoio financeiro da Universidade, mas são autossustentáveis, isto é, o NL-UFES é responsável pela captação de recursos que garantem seu sustento financeiro.

Uma das principais fontes de captação de renda do NL-UFES é o projeto Cursos de Línguas, que oferta cursos de idiomas (Inglês, Francês, Espanhol, Italiano e Alemão) para cerca de 4.500 pessoas da comunidade capixaba, ao valor semestral de $\mathrm{R} \$ 580,00$, um preço mais 
baixo que os aplicados no mercado das escolas de idiomas. Parte das vagas são ofertadas como bolsa para alunos da escola pública, da graduação e servidores da UFES.

Entre os dias 17 de março e 01 de junho, o NL-UFES seguiu a determinação da UFES em suspender as aulas presenciais e não propor formas de ensino remoto, acreditando que seria possível um retorno à normalidade em um curto ou médio prazo de tempo (NL-UFES, 2020a; 2020b; 2020c; 2020d). Nesse período, os seus gestores precisaram tomar decisões importantes, considerando a complexidade envolvida na realização das atividades do projeto.

Para embasar as decisões, foi enviado aos alunos e alunas de todos os idiomas, um questionário com vistas a recolher informações acerca do acesso dos(as) estudantes a tecnologias da informação e da disponibilidade em realizar os cursos remotamente. Nesse período, uma outra medida do NL-UFES foi a de propor ações para manter contato com os(as) alunos(as) por meio das mídias sociais (especialmente Facebook e Instagram) e envio de atividades não obrigatórias por meio de endereço eletrônico.

Em meados de maio, decidiu-se pelo início das aulas virtuais síncronas por meio da plataforma Microsoft Teams (NL-UFES, 2020e), implementadas a partir de 02 de junho. Tal medida foi considerada, porque a manutenção do projeto Cursos de Línguas está diretamente ligada à captação de recursos por meio das semestralidades. Isto é, o NL-UFES julgou que não poderia aguardar uma decisão da Reitoria da UFES sobre a retomada de aulas (presenciais ou remotas) na graduação, visto que a não oferta de um segundo semestre letivo inviabilizaria o projeto.

É importante salientar as motivações para a escolha da plataforma de ensino e a escolha do formato dos cursos remotos, por parte dos gestores do NL-UFES: a plataforma Microsoft Teams foi escolhida por facilitar o controle dos trabalhos do ponto de vista institucional; e a manutenção das aulas síncronas, para que o curso se mantivesse o mais próximo possível do presencial, no que tange aos horários estabelecidos previamente e aos encontros síncronos.

Observa-se, nesta tomada de decisão, um anseio por replicar o modelo presencial. Como consequência disso, realizou-se uma passagem da modalidade presencial à virtual muito brusca. Isto é, não houve um processo de adaptação e reflexão de uma prática de ensino típica da sala de aula convencional a práticas inovadoras.

Um exemplo da dificuldade de transposição do processo de ensino-aprendizagem de língua estrangeira está presente em uma das perguntas do questionário de avaliação do semestre enviado ao alunado no final do curso. Eles deveriam responder se concordavam ou discordavam com a seguinte afirmação: "consigo copiar no caderno o que é compartilhado na aula". 
Tal preocupação aponta para o modo como a instituição e seus dirigentes compreendem a concepção de ensino-aprendizagem de LE, em que elementos como caderno, cópia do quadro (físico ou virtual) e necessidade de material impresso são itens indispensáveis para um resultado positivo no processo de aquisição linguística, o que não coaduna, necessariamente, com uma proposta de curso virtual de idiomas.

Por um lado, parece que a presença do professor na condução do aprendizado dos estudantes é fundamental para a instituição e seus agentes. Por outro lado, corre-se o risco de que as expectativas sejam frustradas, considerando a imensa distância entre o presencial e o remoto no contexto de ensino de LE. Some-se a isso o fato de que o corpo discente também indica preferência por formas habituais de aprendizagem, como mostrou a pesquisa de avaliação do curso, em que 75,6\% dos estudantes afirmaram que "mesmo usando a plataforma digital, ainda preferem escrever no caderno".

Essa visão de ensino com o uso de material predominantemente impresso foi apontada pelos respondentes do questionário. Dentre os concluintes do curso, 55,1\% afirmaram preferir ter acesso a materiais impressos em detrimento de materiais virtuais, reforçando a ideia de que é necessário um suporte físico para subsidiar o processo de ensino-aprendizagem. Além disso, o fato de que $67,7 \%$ dos alunos que concluíram o semestre letivo no modelo virtual afirmaram que preferem aulas presenciais.

Antes de discorrermos sobre a transposição do curso de uma modalidade à outra, queremos ilustrar, no tópico subsequente, o formato do curso de francês tradicionalmente ofertado pelo NL-UFES. Nesse sentido, a seção seguinte será dedicada a descrever o curso no que tange aos níveis ofertados, quantitativo de alunos, material didático utilizado, entre outras informações relevantes para nossa análise.

\section{$O$ curso de francês do NL-UFES}

O curso de francês no NL-UFES está organizado em oito níveis (Francês 01 a Francês 08) e, para os que já têm conhecimentos intermediários da língua e querem aprimorar a fluência, é ofertado um curso de Conversação. Os cursos são semestrais, integralmente presenciais e têm duração de 55 horas. As avaliações são padronizadas por nível e aplicadas em três momentos, com base em quatro habilidades (oralidade, escuta, escrita e leitura). Para cada habilidade é atribuído um conceito que varia de A a D.

Trata-se de um dos maiores projetos de extensão da Universidade no sentido de alcançar um grande quantitativo de pessoas. No primeiro semestre de 2020, foram ofertadas 42 turmas, 
abarcando 677 estudantes: Francês 01 (10 turmas); Francês 02 (09 turmas); Francês 03 (06 turmas); Francês 04 (04 turmas); Francês 05 (04 turmas); Francês 06 (03 turmas); Francês 07 (03 turmas); Francês 08 (02 turmas); Conversação (01 turma). Tais dados evidenciam o tamanho do projeto, bem como a evasão ao longo do percurso formativo.

Embora não tenha sido realizada nenhuma pesquisa formal sobre os fatores que costumeiramente levam à evasão, os gestores observam que os índices de abandono vêm aumentando a partir de 2016, com a crise econômica vivenciada no Brasil.

As aulas são ministradas por uma equipe composta de professores(as) contratados(as) em regime de CLT pela FEST e estagiários(as) oriundos(as) do curso de Licenciatura Dupla Português e Francês da UFES. No início do semestre, havia 08 docentes e 01 estagiária. Todos(as) são formados(as) em Letras: dois com habilitação em Francês pela UFES e outros dois em vias de concluírem uma segunda graduação, em Francês, também pela UFES. Ou seja, a equipe de docentes tem sólida formação na área, além de estarem em constante formação.

O material didático adotado pelo NL-UFES é o livro Entre Nous, da editora Maison des Langues: composto por 4 livros, sendo que cada livro corresponde a dois níveis de francês, ou seja, é utilizado por um ano. Trata-se de material importado, a ser adquirido(a) pelo aluno(a), a um custo de, em média, R\$200,00 cada livro. Em sala de aula, não é permitido que se utilizem cópias do material. Assim, além da semestralidade, há o custo com material didático.

Percebe-se que o curso de francês do NL-UFES segue os moldes tradicionais de cursos livres de idiomas e cumpre papel social relevante para a comunidade externa e interna à UFES, promovendo o ensino do idioma a públicos e interesses variados: de jovens a partir de 15 anos até pessoas da terceira idade; universitários; interessados de modo geral; de extratos sociais diversos. Por conta dessa heterogeneidade de público, a adoção e aceitação do ensino remoto promoveram desdobramentos que merecem nossa atenção.

\section{Acesso de alunos(as) de francês do NL-UFES às TDICs}

Com a vinda da pandemia e a impossibilidade de dar continuidade às aulas presenciais, houve preocupação sobretudo com uma evasão massiva que pudesse vir a comprometer a existência do projeto, uma vez que os recursos para pagamento de professores, funcionários, equipamentos e manutenções vêm unicamente do pagamento da semestralidade dos cursos. Por isso, a alternativa encontrada para a solução desse problema foi a virtualização das aulas.

Para subsidiar as discussões sobre o assunto, no início de abril, foi enviado a todos(as) os(as) alunos(as) do NL-UFES um questionário planejado pelas coordenações administrativa, 
pedagógica e geral. O questionário foi elaborado no GoogleForms, contendo 13 questões fechadas e uma aberta, relativas ao uso de redes sociais, ao conhecimento de plataformas digitais, ao acesso à internet e à disponibilidade de aparelhos eletrônicos.

Em uma população de 4.500 alunos matriculados (sendo 677 de francês), houve uma amostra de 2940 respostas (sendo 440 de francês). Considerando a totalidade de alunos(as) do Núcleo de Línguas, 65,3\% responderam. Levando em conta apenas os(as) alunos(as) de francês, $64,9 \%$ responderam. Trata-se, portanto, de uma amostragem bastante representativa da realidade do público do NL-UFES.

Constatou-se, por meio da pesquisa, que $93,86 \%$ dos alunos possuem o livro didático. O fato de o questionário trazer esta preocupação demonstra que, para o NL-UFES, esse elemento pode facilitar a condução da aula em um contexto não presencial, no sentido de que os estudantes têm um suporte físico em mãos. Porém, um dos pontos levantados pelos(as) professores(as) em reuniões é que as atividades propostas pelo livro pressupõem interação presencial entre os alunos e, portanto, foram necessárias adaptações.

Levou-se um tempo para que se familiarizassem com a plataforma e pensassem em formas de adaptar as atividades do livro às possibilidades de interação via plataforma, de modo que a abordagem comunicativa não ficasse comprometida: inicialmente, as aulas ganharam um caráter mais expositivo, os conteúdos do livro didático foram transmitidos mais rapidamente do que o previsto na modalidade presencial e, por essa razão, foi preciso complementar o curso com atividades e materiais extras.

\begin{abstract}
Embora, a tecnologia seja um elemento da cultura bastante expressivo, ela precisa ser devidamente compreendida em termos das implicações do seu uso no processo de ensino e aprendizagem. Esta compreensão é que permite ao professor integrá-la à prática pedagógica [...] para isto é fundamental que o professor, independente da sua área de atuação, possa conhecer as potencialidades e limitações pedagógicas envolvidas nas diferentes tecnologias, seja o vídeo, a Internet, o computador entre outras [...] (SILVA; MEDEIROS; SANTOS, 2016, p. 231).
\end{abstract}

Outra questão importante a ser lembrada é o fato de 6,14 \% dos alunos não possuírem livro didático. Quando as aulas eram presenciais, havia a possibilidade de empréstimo por meio da biblioteca do NL-UFES ou de se acompanhar as aulas com um companheiro de classe, compartilhando o material. Com a virtualização, esses alunos provavelmente tiveram mais dificuldades. É preciso dizer que o material didático pode ser consultado em sua totalidade no espaço virtual da editora, porém, com custo ao aluno. 
A pesquisa revelou que apenas $36.82 \%$ deles tinham o hábito de acessar a plataforma virtual da editora. Isso é relevante à medida em que os estudantes não previam que o conteúdo do curso de francês também possa ser acessado virtualmente: a práxis era, para a maioria, de um aprendizado baseado exclusivamente na interação presencial em sala de aula.

Considerando que a quase totalidade dos alunos respondeu que tinha acesso à internet $\mathrm{e}$ a equipamentos como computadores e smartphones, sugere-se que não é a falta de recursos tecnológicos que os impedia de terem acesso a conteúdos extras e virtuais. Isso aponta para uma falta de ambientação ao virtual em relação ao aprendizado de língua estrangeira.

Os dados sugerem que os alunos faziam uso da internet, das redes sociais e de plataformas como o Youtube. Além disso, mais de 93\% respondeu que "estaria disposto a acessar e ter acesso aos conteúdos e/ou atividades on-line por meio de outros canais como blog, plataformas e outras ferramentas". Não fica claro, pela pergunta realizada no questionário, se essa abertura dos alunos aos conteúdos virtuais dizia respeito a uma efetiva retomada das aulas no intuito de se concluir o curso virtualmente.

Uma vez retomadas as aulas, a maioria dos alunos permaneceu matriculada, manifestando desejo de tentar estudar de um modo diferente do habitual, ou seja, a maioria imaginou que havia condições de realizar o curso remotamente. Para os reticentes, os professores foram orientados a os estimular a não desistirem antes de experienciarem o ensino remoto.

Antes de experienciarem o ensino remoto, de maneira propriamente dita, outras formas de interação virtual entre professores e alunos foram propostas pela equipe gestora do NLUFES, a saber: contatos por meio de redes sociais, e-mail e aplicativos de mensagens. Na seção subsequente, iremos relatar como se deram tais interações.

\section{As primeiras interações virtuais}

Antes de optar pela implementação do ensino virtual, a gestão do NL-UFES solicitou que os professores de cada idioma estabelecessem interações com os alunos. O objetivo era que os estudantes não perdessem contato com as línguas estudadas e mantivessem vínculo com a instituição. Foi recomendado que se proporcionassem conteúdos leves, objetivos, pontuais, por meio de plataformas virtuais e/ou redes sociais, abordando assuntos como: vocabulário, gramática, vídeos, curiosidades, visitas virtuais a museus, teatros, bibliotecas.

Nesse período, a editora cedeu aos professores acesso à versão premium do espaço virtual, que permite a utilização de todos os recursos do livro e, por sua vez, esses se lançaram 
em novos mares: experienciaram formas diversas de interação virtual e se familiarizaram um pouco mais com o espaço virtual da editora Maison des Langues, identificando as possibilidades de trabalho remoto junto aos alunos.

A aproximação entre alunos e docentes por meio de recursos virtuais se deu via redes sociais do curso de francês (página do Facebook e Instagram), grupos de Whatsapp e e-mail. Semanalmente, os alunos recebiam uma atividade virtual cultural ou uma dica de estudos, de acordo com o nível cursado. Além disso, os professores permaneciam à disposição para feedback virtual referente às atividades postadas.

Salientou-se que tais atividades não seriam consideradas como "aulas dadas" ou substitutas de carga horária presencial, embora os temas e conteúdos privilegiados tenham sido aqueles que se relacionavam com as unidades dos livros didáticos. Pode-se observar que houve um aumento no número de seguidores nas redes sociais, assim como do número de curtidas das postagens, ou seja, o contato entre a instituição e alunos foi intensificado, conforme almejado pela direção do NL-UFES.

Cabe ressaltar que houve um envolvimento dos profissionais docentes desde a seleção e elaboração de atividades, culminando em encontros virtuais por meio de plataformas variadas à escolha do docente, como Zoom, Skype e YouTube. Tais ocasiões configuraram-se como conversas virtuais acerca de assuntos culturais, bem como "aulões" e lives, sobre conteúdos já ministrados presencialmente e abertos a todos os alunos matriculados no curso.

Esse momento foi bastante positivo no sentido de que se ambientassem com as interações virtuais, com a prática do estudo autônomo, com uma nova organização de vida e de trabalho exigida pelo contexto de pandemia e isolamento.

No entanto, o questionário avaliativo sobre o curso demonstrou que essas ações não foram suficientes para promover uma conexão mais expressiva entre o NL-UFES e os alunos, uma vez que $18,9 \%$ afirmaram que não se sentiram conectados ao curso de francês por meio das atividades e $31,5 \%$ se manifestaram indiferentes a essa iniciativa.

No tópico a seguir, pretendemos pormenorizar de que maneira se deu a implementação do ensino remoto no curso de francês do Núcleo de Línguas da UFES, tentando salientar os desdobramentos e implicações das adaptações metodológicas necessárias à continuidade do processo de ensino-aprendizagem. 


\section{Implementação do ensino remoto e adaptações metodológicas}

Em meados de maio, a direção tomou a decisão de promover um retorno às atividades de maneira virtual, por meio de plataformas. Foram testadas Google classroom e Microsoft Teams, a qual foi escolhida pelos seguintes motivos: maior controle dos trabalhos realizados e o uso mais próximo possível da realidade e da normalidade. Optou-se por dar continuidade às aulas em dias e horários conforme os previstos para o ensino presencial, no início do semestre, de forma síncrona, segundo comunicado anunciado no site do NL-UFES:

Após avaliação de várias possibilidades, foi escolhida a plataforma Microsoft Teams, uma das ferramentas do Microsoft Office Online, disponível gratuitamente para instituições de ensino. Essa plataforma permitirá o contato e a interação entre estudantes e professores, possibilitando a realização de aulas síncronas e as trocas em vídeo, texto e áudio nos horários de aula, com a devida segurança no intercâmbio de informações e no registro dos dados. Dessa forma, será possível oferecer uma adaptação eficiente das atividades de ensino-aprendizagem dos cursos do Núcleo de Línguas a essa nova modalidade (NL-UFES, 2020e, grifo no original).

À minoria que declarou no questionário não possuir condições estruturais, seria dada a opção de um plano de estudos impresso, disponibilizado para retirada nas dependências do NLUFES, com atividades a serem realizadas autonomamente pelo estudante.

Como medida de apoio aos docentes, a coordenação pedagógica promoveu uma tarde formativa, ou seja, um ateliê de treinamento para o uso da plataforma, de modo a capacitá-los para usar as ferramentas do ambiente virtual. Em caráter adicional, foi ofertada uma palestra com uma psicóloga, no intuito de promover um diálogo sobre as questões emocionais vivenciadas no período.

Eles foram orientados a interagirem entre si e com os alunos por meio da plataforma escolhida, a fim de praticarem a nova modalidade e interagirem com o ambiente virtual antes do início oficial da retomada de aulas. Em 02 de junho de 2020, com a implementação de aulas virtuais síncronas (NL-UFES, 2020e), passou-se a uma nova fase do ensino de LE no NL-UFES durante a pandemia.

Não houve participação docente na escolha da plataforma e os professores afirmaram que houve pouco tempo de preparação para o uso do ambiente de aprendizagem virtual (AVA) determinado, o que acabou por suscitar sentimentos de angústia, estresse e insegurança, corroborando a afirmação de Kaspary (2012, p. 35), quando diz: “[...] não é possível avaliar, coordenar e propor tarefas dentro de um meio no qual não se sente confortável”. 
Nas primeiras semanas, eles evidenciaram sobretudo a angústia de não terem domínio suficiente sobre os recursos da plataforma para auxiliarem alunos com dificuldades. Além disso, houve o receio de que qualquer problema de ordem técnica fosse interpretado como falta de cuidado e preparação para a aula. Isso mostra que “[...] aplicar conhecimentos recém adquiridos não é uma tarefa imediata, exigindo todo um período de experimentação, a fim de se obter domínio da nova tecnologia" (BIANCHINI, 2003, p. 30).

Alguns fatores positivos também foram suscitados: alunos(as) ansiosos por uma volta às aulas, abertos a experienciar a modalidade virtual, saudosos dos professores e colegas.

A dinâmica da "nova" sala de aula impôs reflexões acerca da metodologia utilizada, uma vez que surgiram novos elementos que desafiavam a práxis habitual: velocidade baixa de internet, falta de conhecimento da plataforma, alunos que não possuíam microfone, distrações do ambiente doméstico que prejudicavam a concentração e câmeras desligadas que faziam com que o professor não se conectasse com os indivíduos para os quais falava. Tudo isso, corroborou para que a aula tivesse menos fluidez quando comparada à realidade presencial.

Para autores como Silva, Medeiros e Santos (2016), o uso de TDICs vem se configurando como um "precioso auxílio" ao ensino de línguas estrangeiras. De fato, enquanto forma de "auxílio" ao curso presencial, professores e alunos do NL-UFES estavam - mesmo antes da pandemia - habituados às potencialidades da web: interação por meio de Whatsapp e redes sociais e pesquisas em smartphones sobre um tema trazido pelo livro didático, conferindo dinamismo às aulas.

No entanto, tal passagem do presencial ao virtual trouxe "[...] preocupação, a ansiedade, justamente em relação ao bom funcionamento do material e a falta de suporte técnico quando surge algum problema” (GALLI; AUBIN, 2012).

As dificuldades fazem com que os recursos tecnológicos passem a ser vistos como um "corpo estrangeiro" que suscitaria um certo número de medos antes de entrar nos hábitos pedagógicos: o medo de perder a credibilidade, de ter sua competência julgada pelos alunos caso o material não funcione. Essas são algumas razões que freiam o entusiasmo dos professores no recurso às novas tecnologias para a aprendizagem, que são, muitas vezes, percebidas como um elemento "estrangeiro". (GALLI; AUBIN, 2012).

Além das preocupações de ordem técnica, houve aquelas de caráter metodológico. Os professores lidaram com novas expectativas por parte dos alunos. Dentre elas, a disponibilização dos materiais das aulas com antecedência para que eles tivessem um primeiro contato com os conteúdos que seriam abordados em aula. No questionário avaliativo, 82,7\% dos alunos afirmou que o envio prévio de materiais funcionou como um elemento facilitador. 
Desse modo, cria-se para o professor uma demanda que não era comum anteriormente: a preparação de aulas com maior antecedência que o usual e o compartilhamento prévio de mídias, materiais e conteúdos com os(as) estudantes.

Um dos maiores desafios foi o de proporcionar que os alunos interagissem entre si e com o(a) professor(a). Aos poucos, esse desafio foi sendo superado, ao passo que uma maior ambientação à "nova" sala de aula e aos seus ritmos, limitações e potencialidades. Para tanto, foi essencial a liberdade de experimentação no contexto da aula e, também, as reflexões coletivas realizadas nas reuniões semanais.

Ao final do semestre, foi realizada uma pesquisa de avaliação com os alunos acerca da nova modalidade implementada. De um total de 510 alunos que efetivamente concluíram o curso, 128 responderam ao questionário, trazendo dados interessantes para uma análise da conjuntura.

Por exemplo, ao passo que os professores manifestaram inseguranças tanto em relação à condução das aulas em meio digital, quanto à percepção dos alunos sobre sua prática docente, a pesquisa revelou que $89,8 \%$ dos alunos perceberam o professor bem preparado para conduzir a aula. Prova disso, é que 74,8 \% afirmaram que as atividades em grupo foram bem adaptadas para o novo formato virtual.

Refletir sobre a metodologia de ensino e procurar caminhos para superar as dificuldades enfrentadas nesse processo, levou a equipe da área de francês do Núcleo de Línguas da UFES a se debruçar também sobre um elemento muito relevante: as formas de avaliação. No intuito de relatar tal adaptação, na seção seguinte, iremos tratar mais detidamente do tema avaliação.

\section{Avaliação}

Tradicionalmente, nos cursos presenciais, o NL-UFES mantém um sistema avaliativo padronizado para todos os idiomas, divididos em três momentos do semestre, com datas préestabelecidas no calendário acadêmico, ou seja, há semanas reservadas para aplicação de provas. Tais provas têm caráter somativo e aferem conhecimentos das habilidades: expressão e compreensão orais; expressão e compreensão escritas.

Assim que as aulas foram retomadas virtualmente, os estudantes manifestaram preocupação quanto ao processo avaliativo. Entretanto, não se havia ainda discutido os métodos de avaliação a serem utilizados no ensino remoto, o que veio a ocorrer durante o mês de julho de 2020, quando a direção do NL-UFES tomou a decisão de permitir que cada idioma estabelecesse suas formas e datas de avaliação. 
A equipe de francês considerou que uma avaliação somativa poderia trazer carga de estresse ou desestímulo para os alunos, uma vez que as avaliações não poderiam ser pensadas na mesma dinâmica do ensino presencial, dadas as dificuldades técnicas e a apreensão quanto à nova modalidade.

Nesse sentido, optou-se por uma avaliação formativa, constante, flexível por meio de atividades e projetos, ressaltando-se a importância de que o aluno tenha feedbacks ao longo do semestre. Priorizou-se a correção das dificuldades ao longo do percurso de aprendizagem, promovendo o trabalho coletivo e leveza ao processo.

As atividades avaliativas foram aplicadas durante uma aula determinada, por meio de exercícios desenvolvidos a partir do livro didático, com vistas a trabalhar todas as habilidades. Os projetos consistiram em estudos dirigidos e pesquisas em torno de um tema escolhido para cada nível, que culminaram em produções elaboradas pelos alunos como: cartazes, vídeos, poemas, crônicas etc.

Ao final, os produtos gerados foram postados nas redes sociais do francês do NL-UFES como forma de evidenciar e divulgar o resultado dos projetos e valorizar a aprendizagem colaborativa, que prevê uma ação ativa entre alunos e professores, corroborando para o desenvolvimento das habilidades linguísticas e interacionais (NITZKE, 2002).

\section{Evasão}

Antes da retomada das aulas pela plataforma, houve solicitações de cancelamentos de matrículas e devolução de semestralidade, o que gerou na equipe gestora preocupação acerca de uma evasão em massa e a consequente falência do projeto. Por isso, insistiu-se para que os(as) estudantes experienciassem a modalidade virtual antes de pensarem em desistirem.

Com o ensino remoto, a equipe de francês preocupou-se especialmente com a evasão, especialmente no que diz respeito aos alunos bolsistas e aos alunos acima de 60 anos: a exigência do uso de ferramentas digitais e internet os alijaria do aprendizado? A intermediação do computador e a falta do encontro presencial os desestimulariam? Além disso, vários outros elementos preocupantes viriam a desvelar-se no percurso, conforme tentaremos relatar mais adiante.

O quadro 01 (abaixo) ilustra o panorama da evasão no primeiro semestre letivo de 2020, quando houve a interrupção das aulas presenciais e a passagem para o ensino remoto. 
Quadro 1 - Panorama da evasão no curso de francês em 2020/1

\begin{tabular}{|l|l|l|l|l|l|}
\hline & $\begin{array}{l}\text { matrículas } \\
\text { ativas em } \\
\text { março } \\
\text { (ensino } \\
\text { presencial) }\end{array}$ & $\begin{array}{l}\text { matrículas } \\
\text { ativas em } \\
\text { junho } \\
\text { (início do } \\
\text { ensino remoto) }\end{array}$ & $\begin{array}{l}\text { frequência } \\
\text { efetiva de } \\
\text { alunos(as) em } \\
\text { julho }\end{array}$ & $\begin{array}{l}\text { frequência } \\
\text { efetiva de } \\
\text { alunos(as) em } \\
\text { agosto } \\
\text { (fim do } \\
\text { semestre } \\
\text { letivo) }\end{array}$ & $\begin{array}{l}\text { Matrículas } \\
\text { efetuadas no } \\
\text { segundo } \\
\text { semestre } \\
\text { (ensino } \\
\text { remoto) }\end{array}$ \\
\hline Francês 01 & 197 & 195 & 148 & 130 & 26 \\
\hline Francês 02 & 146 & 137 & 116 & 105 & 93 \\
\hline Francês 03 & 98 & 89 & 78 & 75 & 83 \\
\hline Francês 04 & 69 & 68 & 63 & 60 & 47 \\
\hline Francês 05 & 43 & 42 & 40 & 40 & 46 \\
\hline Francês 06 & 40 & 38 & 34 & 34 & 28 \\
\hline Francês 07 & 45 & 44 & 36 & 36 & 26 \\
\hline Francês 08 & 22 & 22 & 20 & 510 & 376 \\
\hline Conversação & 17 & 677 & 14 & 10 & 27 \\
\hline Totais & 635 & & & 26 \\
\hline
\end{tabular}

Fonte: Elaborado pelos autores

Como se pode observar no quadro 01, em março de 2020, havia 677 pessoas matriculadas nos cursos de francês, na modalidade presencial. Com a interrupção das atividades presenciais e, consequentemente, a implementação do ensino remoto, no início de junho de 2020, a maioria permaneceu no quadro de estudantes ativos, ou seja, os estudantes não cancelaram as matrículas.

Dos 677 inscritos no início do período letivo, em março de 2020, 635 permaneceram vinculados ao curso quando da implementação do ensino remoto em junho de 2020. Acreditamos que a alta adesão dos estudantes à aprendizagem por meio da plataforma digital deu-se em virtude dos seguintes fatores: 1) o incentivo dos professores nas primeiras interações virtuais já relatadas sem seção anterior deste artigo; 2) o incentivo aos estudantes à 
experimentação das aulas na modalidade remota e 3) o curto período disponibilizado para cancelamento de matrícula, isto é , uma semana após a retomada das aulas na nova modalidade.

Outro elemento que merece nossa análise é a frequência efetiva dos alunos às aulas na plataforma Microsoft teams. $\mathrm{O}$ fato de haver 635 alunos com matrícula ativa no sistema não dá a ver a realidade do cenário de evasão. Isto é, para abordarmos a questão, é necessário visualizar a frequência efetiva dos alunos no sentido de assistirem às aulas síncronas.

O quadro 01 evidencia dados relevantes para nossa análise. Em julho e agosto, foram realizados levantamentos de alunos frequentes: a presença era baixa em algumas turmas, independentemente dos dias e horários. Muitos alunos relataram aos professores que haviam mantido a matrícula ativa por julgarem que teriam condições de finalizar o curso de modo virtual, mas observaram que a nova realidade de isolamento social trazia elementos novos e uma organização de vida que os afastaram dos estudos.

Dentre os fatores mencionados, estão: isolamento em zona rural (onde não há sinal de internet ou este é insuficiente para a boa utilização da plataforma de ensino); cuidados com idosos e crianças (sobretudo mulheres afirmaram acumular tarefas, reduzindo ou impossibilitando o tempo a ser dedicado aos estudos); a necessidade de compartilhar equipamentos indispensáveis para o acompanhamento das aulas; insegurança e inabilidade para o uso de tecnologias; alterações nos horários de trabalho; surdez; e mudanças de prioridades.

Todos os fatores mencionados acima contribuíram para os índices de evasão ilustrados no Quadro 01. Após o período de cancelamento de matrículas referente ao primeiro semestre de 2020, restaram 635 pessoas inscritas no curso, entretanto 510 alunos finalizaram o semestre letivo. Em outras palavras, a não adesão às aulas virtuais pode ser constatada para além do cancelamento das matrículas, ou seja, foi-se revelando ao longo do período letivo com o abandono progressivo das aulas.

Diante desse cenário, a equipe gestora do Núcleo de Línguas da UFES orientou os professores para que fizessem uma campanha de convencimento aos alunos para que permanecessem matriculados no segundo semestre de 2020. Assim, houve intenso apelo dos docentes aos 510 alunos frequentes para que continuassem seus estudos de francês no NLUFES, ainda de modo remoto.

Por um lado, tal empenho logrou êxito, conforme demonstrado no Quadro 01, uma vez que houve índices consideráveis de rematrículas nas turmas de Francês 02 a Francês 08. Isso quer dizer que os alunos que conseguiram acompanhar as aulas remotas até o final do semestre, em sua maioria, optaram por dar continuidade ao curso. Os dados demonstram que parte significativa dos alunos permaneceu na instituição. 
Por outro lado, constatamos que as inscrições para o Francês 01 no segundo semestre de 2020 tiveram uma queda considerável quando comparado ao semestre anterior: enquanto que em 2020/1 havia matrícula de 197 iniciantes, em 2020/2 houve apenas 26. Com isso, apenas 03 turmas de Francês 01 tiveram quantidade mínima de inscritos para serem abertas, enquanto que, habitualmente, o número de turmas iniciantes era de 10 a 12.

Isso demonstra que a instituição não teve sucesso em angariar novos alunos para o curso de francês, embora tenha havido divulgação sobre o curso nos perfis oficiais da área de francês do NL-UFES (Instagram e Facebook) e também nas redes sociais dos professores.

Se considerarmos o montante total de alunos de francês no NL-UFES antes e depois da implementação do ensino virtual, observamos que o cenário levou à redução expressiva de oferta para o semestre subsequente. Antes da pandemia, o curso costumava contar com cerca de 700 alunos e durante o isolamento social advindo dela, apenas 376 matrículas foram efetuadas. Assim, fica evidente a evasão ocasionada pela nova realidade de ensino remoto, tendo o isolamento social como pano de fundo.

\section{Considerações finais}

Com este artigo, tivemos o objetivo de relatar a experiência de ensino de FLE no NLUFES durante o primeiro semestre letivo de 2020, com vistas a registrar aspectos das mudanças ocorridas no processo de adaptação do ensino presencial para o remoto, dado o contexto de pandemia.

O estudo baseou-se em documentos como atas de reuniões, portarias institucionais, pesquisas realizadas pelo NL-UFES junto ao alunado e em levantamento de dados sobre matrículas efetuadas e evasão. Tais documentos mostraram anseios e angústias quanto à retomada das atividades, bem como o processo de reflexão da equipe de francês, desde as primeiras interações virtuais até a consolidação das aulas síncronas, as adaptações metodológicas e relativas ao modelo de avaliação.

Concluímos que o acesso às TDICs foram fundamentais para essa transição, muito embora insuficientes para impedir houvesse evasão. Outra conclusão importante tem a ver com a formação docente: embora os professores tivessem sólida experiência, o advento desse novo formato educativo gerou incertezas e inseguranças no grupo.

No entanto, o trabalho colaborativo permitiu minimizar as adversidades, já que procuraram soluções criativas para os obstáculos, de modo a promover leveza sem perder o 
foco da aprendizagem, como evidenciou a repercussão dos projetos desenvolvidos pelos alunos e postados nas redes sociais.

O cenário relatado neste trabalho evidenciou um processo que já vinha ocorrendo no universo da educação, a saber: a virtualização de cursos de idiomas. Entretanto, deu-se neste contexto de modo acelerado, dadas as circunstâncias do isolamento social imposto. Acreditamos que a experiência demonstrada marcadamente no contexto do NL-UFES seja parecida com outras em nível nacional e internacional.

A experiência, embora tenha aspectos negativos, configurou-se positivamente como uma possibilidade de aprendizagem de novas maneiras de se chegar a públicos antes não alcançados, o que fez com que a direção do NL-UFES manifestasse o desejo de que o ensino remoto permanecesse como uma realidade para além do período de pandemia, com vistas a atender pessoas de outras localidades, longe da capital Vitória.

AGRADECIMENTOS: Agradecemos a Ivan Mamede Carlos pela gentileza de tabular as planilhas com os dados extraídos a partir dos questionários utilizados nesta pesquisa.

\section{REFERÊNCIAS}

BIANCHINI, D. SALVI - sala de aula virtual: contribuição para a comunicação síncrona em educação mediada por computador. 2003. 239 f. Tese (Doutorado em Educação) Universidade Estadual de Campinas, Campinas, 2003. Disponível em: http://repositorio.unicamp.br/bitstream/REPOSIP/253203/1/Bianchini_David_D.pdf. Acesso em: 09 jul. 2020.

GALLI, J. A.; AUBIN, S. P. B. O uso do livro didático digital em francês na Ufpe. In: $4^{\circ}$ SIMPÓSIO HIPERTEXTO E TECNOLOGIAS NA EDUCAÇÃO, 4., 2012, Recife. Anais [...]. Recife, PE: Universidade Federal de Pernambuco, 2012. Disponível em: http://www.nehte.com.br/simposio/anais/Anais-Hipertexto-2012/JoiceGalli\&SimoneAubinOusodolivro.pdf. Acesso em: 09 jul. 2020.

GOVERNO DO ESPÍRITO SANTO. Secretaria da Saúde confirma primeiro caso do novo coronavírus no Espírito Santo. 6 mar. 2020a. Disponível em:

https://www.es.gov.br/Noticia/secretaria-da-saude-confirma-primeiro-caso-do-novocoronavirus-no-espirito-santo. Acesso em: 23 de jun. de 2020.

GOVERNO DO ESPÍRITO SANTO. Decreto n. 4597-r, de 16 de março de 2020. que dispõe sobre as medidas para enfrentamento da emergência de saúde pública decorrente do coronavírus (COVID-19) na área da educação, e dá outras providências. Votória, ES, 17 mar. 2020b. Disponível em:

https://coronavirus.es.gov.br/Media/Coronavirus/Legislacao/DECRETO $\% 20 \mathrm{~N} \% \mathrm{C} 2 \% \mathrm{BA} \% 20$ 
4597-R,\%20DE\%2016\%20DE\%20MAR\%C3\%87O\%20DE\%202020.pdf. Acesso em: 23 de jun. de 2020.

KASPARY, C. V. Percursos de Leitura em FLE à distância. 2012. 184 f. Dissertação (Mestrado) - Universidade Federal do Rio Grande do Sul, Porto Alegre, 2012. Disponível em: https://lume.ufrgs.br/handle/10183/56025. Acesso em: 09 jul. 2020.

MAGNONI, A. F.; SILVA, S. R. O desafio da interação no ensino de língua estrangeira em cursos on-line e presenciais nas escolas públicas paulistas. Revista Educação e Linguagens, Campo Mourão, v. 3, n. 5, jul./dez. 2014. Disponível

em:http://www.fecilcam.br/revista/index.php/educacaoelinguagens/article/viewFile/671/406. Acesso em: 09 jul. 2020.

NITZKE, J. A. et al. Criação de ambientes de aprendizagem colaborativa. X SBIE, Curitiba, 1999. Disponível em:

http://penta.ufrgs.br/pgie/sbie99/acac.html\#: :text=A\%20cria $\% \mathrm{C} 3 \% \mathrm{~A} 7 \% \mathrm{C} 3 \% \mathrm{~A} 3 \mathrm{o} \% 20 \mathrm{de} \% 2$ 0ambientes $\% 20$ de,Piaget $\% 20 \mathrm{e} \% 20$ Vygotski\%2C\%20entre\%20utras. Acesso em: 09 jul. 2020.

NÚCLEO DE LÍNGUAS - UFES. Núcleo de Línguas suspende atividades acadêmicas e administrativas a partir desta terça-feira, 17. 19 mar. 2020a. Disponível em:

http://www.nucleodelinguas.ufes.br/conteudo/nucleo-de-linguas-suspende-atividadesacademicas-e-administrativas-partir-desta-terca-feira. Acesso em: 23 jun. 2020.

NÚCLEO DE LÍNGUAS - UFES. Ufes prorroga até 6 de abril prazo para reorganização das atividades presenciais. 26 mar. 2020b. Disponível em:

http://www.nucleodelinguas.ufes.br/conteudo/ufes-prorroga-ate-6-de-abril-prazo-parareorganizacao-das-atividades-presenciais. Acesso em: 23 jun. 2020.

\section{NÚCLEO DE LÍNGUAS - UFES. Prorrogação da suspensão das atividades presenciais} até 30 de abril. 06 abr. 2020c. Disponível em:

http://www.nucleodelinguas.ufes.br/conteudo/prorrogacao-da-suspensao-das-atividadespresenciais-ate-30-de-abril. Acesso em: 23 jun. 2020.

\section{NÚCLEO DE LÍNGUAS - UFES. Nova prorrogação da suspensão das atividades}

presenciais até 30 de maio. 30 abr. 2020d. Disponível em:

http://www.nucleodelinguas.ufes.br/conteudo/nova-prorrogacao-da-suspensao-das-atividadespresenciais-ate-30-de-maio. Acesso em: 23 jun. 2020.

NÚCLEO DE LÍNGUAS - UFES. Retomada das aulas do semestre letivo 2020/1. 22 maio 2020e. Disponível em: http://www.nucleodelinguas.ufes.br/conteudo/retomada-das-aulas-dosemestre-letivo-20201. Acesso em: 23 jun. 2020.

PREFEITURA DE VITÓRIA. Decreto n. 18047, de 20 de março de 2020. Dispõe sobre medidas para enfrentamento da emergência de saúde pública de importância internacional decorrente do novo coronavírus e dá outras providências. Vitória, ES, 2020. Disponível em: https://www.legisweb.com.br/legislacao/?id=391351. Acesso em: 23 jun. 2020.

SILVA, A. K. T.; MEDEIROS, C. E.; SANTOS, L. A. Novas tecnologias aplicadas em salas de aula: interatividade no ensino de línguas. In: Reflexões sobre o ensino-aprendizagem de 
línguas estrangeiras. Campina Grande: Eduepb, 2016. p. 229-243. Disponível em: http://www.uepb.edu.br/download/ebooks/Reflexo\%25CC\%2583es-sobre-o-ensinoaprendizagem-de-li\%25CC\%2581nguas-estrangeiras.pdf. Acesso em 09 jul. 2020.

UFES. Resolução 04/2020 CUN/UFES. Regulamenta a reorganização das atividades acadêmicas, administrativas e eventos no âmbito da Ufes a partir de 17/3/2020, como medida de prevenção ao COVID-19. Vitória, ES, 2020b. Disponível em:

http://www.daocs.ufes.br/sites/daocs.ufes.br/files/field/anexo/resolucao_no_04.2020_suspensao_das_atividades_0.pdf\#overlay-context=resolucoes-de-2020-cun. Acesso em: 23 jun. 2020.

UFES. Resolução 07/2020 CUN/UFES. Regulamenta a reorganização das atividades acadêmicas, administrativas e eventos no âmbito da Ufes como medida de prevenção à Covid19. Vitória, ES, 2020c. Disponível em:

http://ufes.br/sites/default/files/anexo/resolucao_no_07.2020_-_cun_1.pdf. Acesso em: 23 jun. 2020.

UFES. DECISÃO - AD REFERENDUM. Gabinete da Reitoria, 30 abr. 2020d. Disponível em: http://ufes.br/sites/default/files/anexo/ad referendum.pdf. Acesso em 23 jun. 2020.

UFES. Suspensão das atividades presenciais vai até 30 de junho. Ufes declara luto pelas vítimas da COVID. 28 maio 2020e. Disponível em: http://ufes.br/conteudo/suspensao-dasatividades-presenciais-vai-ate-30-de-junho-ufes-declara-luto-pelas-vitimas-da. Acesso em: 23 jun. 2020.

UFES. Ufes cria grupo para planejar retorno das aulas. Atividades presenciais continuam suspensas. 27 abril 2020f. Disponível em: http://ufes.br/conteudo/ufes-cria-grupo-paraplanejar-retorno-das-aulas-atividades-presenciais-continuam-suspensas. Acesso em: 23 jun. 2020.

UFES. Pesquisa com estudantes busca identificar condições de acesso a tecnologias de informação. 05 maio 2020g. Disponível em: http://ufes.br/conteudo/pesquisa-comestudantes-busca-identificar-condicoes-de-acesso-tecnologias-de-informacao. Acesso em: 23 jun. 2020.

UFES. Proposta de Plano de Contingência será encaminhada aos Centros de Ensino. 22 maio 2020h. Disponível em: http://ufes.br/conteudo/proposta-de-plano-de-contingencia-seraencaminhada-aos-centros-de-ensino. Acesso em: 23 jun. 2020.

UFES. Ufes apresenta versão preliminar de planos para enfrentar a pandemia. 26 maio 2020i. Disponível em: http://ufes.br/conteudo/ufes-apresenta-versao-preliminar-de-planospara-enfrentar-pandemia. Acesso em: 23 jun. 2020.

UFES. Ofertar capacitação para o trabalho remoto será uma das prioridades da nova gestão da Progep. 03 jun. 2020j. Disponível em: http://ufes.br/conteudo/ofertar-capacitacaopara-o-trabalho-remoto-sera-uma-das-prioridades-da-nova-gestao-da. Acesso em: 23 jun. 2020.

UFES. Educação a Distância da Ufes disponibiliza vídeos sobre preparação de aulas online. 08 jun. 2020k. Disponível em: http://ufes.br/conteudo/educacao-distancia-da-ufesdisponibiliza-videos-sobre-preparacao-de-aulas-line. Acesso em: 23 jun. 2020. 


\section{Como referenciar este artigo}

PAIXÃO, G. A.; PORSETTEO, I. C. O ensino de francês no núcleo de línguas da Universidade Federal do Espírito Santo durante pandemia de COVID-19. Rev. EntreLínguas, Araraquara, v. 7, n. 00, p. e021002, 2021. e-ISSN: 2447-3529. DOI: https://doi.org/10.29051/el.v7i1.15020

Submetido em: 07/03/2021

Revisões requeridas: 30/03/2021

Aprovado em: 09/04/2021

Publicado em: 01/06/2021 